\title{
Membrane of the Smooth Endoplasmic Reticulum
}

National Cancer Institute

\section{Source}

National Cancer Institute. Membrane of the Smooth Endoplasmic Reticulum. NCI

Thesaurus. Code C33085.

A lipid bilayer enclosing the portion of the endoplasmic reticulum that is free of ribosomes. 